Edith Cowan University

Research Online

ECU Publications 2013

$1-1-2013$

\title{
The genetic contribution of CIDEA polymorphisms, haplotypes and loci interaction to obesity in a Han Chinese population
}

Jingjing Wu

Ling Zhang

Jie Zhang

Ying Dai

Lili Bian

See next page for additional authors

Follow this and additional works at: https://ro.ecu.edu.au/ecuworks2013

Part of the Medicine and Health Sciences Commons

10.1007/s11033-013-2671-7

This is an Author's Accepted Manuscript of: Wu, J., Zhang, L., Zhang, J., Dai, Y., Bian, L., Song, M., Russell, A. C., \& Wang, W. (2013). The genetic contribution of CIDEA polymorphisms, haplotypes and loci interaction to obesity in a Han Chinese population. Molecular Biology Reports: an international journal on molecular and cellular biology, 40(10), 5691-5699. The final publication is available at Springer via here This Journal Article is posted at Research Online. https://ro.ecu.edu.au/ecuworks2013/749 


\section{Authors}

Jingjing Wu, Ling Zhang, Jie Zhang, Ying Dai, Lili Bian, Manshu Song, Alyce C. Russell, and Wei Wang 
Dear Author,

\section{Springer}

Here are the proofs of your article.

- You can submit your corrections online, via e-mail or by fax.

- For online submission please insert your corrections in the online correction form. Always indicate the line number to which the correction refers.

- You can also insert your corrections in the proof PDF and email the annotated PDF.

- For fax submission, please ensure that your corrections are clearly legible. Use a fine black pen and write the correction in the margin, not too close to the edge of the page.

- Remember to note the journal title, article number, and your name when sending your response via e-mail or fax.

- Check the metadata sheet to make sure that the header information, especially author names and the corresponding affiliations are correctly shown.

- Check the questions that may have arisen during copy editing and insert your answers/ corrections.

- Check that the text is complete and that all figures, tables and their legends are included. Also check the accuracy of special characters, equations, and electronic supplementary material if applicable. If necessary refer to the Edited manuscript.

- The publication of inaccurate data such as dosages and units can have serious consequences. Please take particular care that all such details are correct.

- Please do not make changes that involve only matters of style. We have generally introduced forms that follow the journal's style.

Substantial changes in content, e.g., new results, corrected values, title and authorship are not allowed without the approval of the responsible editor. In such a case, please contact the Editorial Office and return his/her consent together with the proof.

- If we do not receive your corrections within $\mathbf{4 8}$ hours, we will send you a reminder.

- Your article will be published Online First approximately one week after receipt of your corrected proofs. This is the official first publication citable with the DOI. Further changes are, therefore, not possible.

- The printed version will follow in a forthcoming issue.

\section{Please note}

After online publication, subscribers (personal/institutional) to this journal will have access to the complete article via the DOI using the URL: http://dx.doi.org/[DOI].

If you would like to know when your article has been published online, take advantage of our free alert service. For registration and further information go to: http://www.springerlink.com.

Due to the electronic nature of the procedure, the manuscript and the original figures will only be returned to you on special request. When you return your corrections, please inform us if you would like to have these documents returned. 


\section{Metadata of the article that will be visualized in OnlineFirst}

\begin{tabular}{|c|c|c|}
\hline \multicolumn{3}{|c|}{ Please note: Images will appear in color online but will be printed in black and white. } \\
\hline ArticleTitle & \multicolumn{2}{|c|}{$\begin{array}{l}\text { The genetic contribution of CIDEA polymorphisms, haplotypes and loci interaction to obesity in a Han } \\
\text { Chinese population }\end{array}$} \\
\hline \multicolumn{3}{|l|}{ Article Sub-Title } \\
\hline Article CopyRight & \multicolumn{2}{|c|}{$\begin{array}{l}\text { Springer Science+Business Media Dordrecht } \\
\text { (This will be the copyright line in the final PDF) }\end{array}$} \\
\hline Journal Name & \multicolumn{2}{|c|}{ Molecular Biology Reports } \\
\hline \multirow[t]{11}{*}{ Corresponding Author } & Family Name & Zhang \\
\hline & Particle & \\
\hline & Given Name & Ling \\
\hline & Suffix & \\
\hline & Division & Department of Epidemiology and Biostatistics, School of Public Health \\
\hline & Organization & Capital Medical University \\
\hline & Address & 100069, Beijing, People's Republic of China \\
\hline & Division & \\
\hline & Organization & Beijing Municipal Key Laboratory of Clinical Epidemiology \\
\hline & Address & 100069, Beijing, People’s Republic of China \\
\hline & Email & zlilyepi@ccmu.edu.cn \\
\hline \multirow[t]{20}{*}{ Corresponding Author } & Family Name & Wang \\
\hline & Particle & \\
\hline & Given Name & Wei \\
\hline & Suffix & \\
\hline & Division & Department of Epidemiology and Biostatistics, School of Public Health \\
\hline & Organization & Capital Medical University \\
\hline & Address & 100069, Beijing, People's Republic of China \\
\hline & Division & \\
\hline & Organization & Beijing Municipal Key Laboratory of Clinical Epidemiology \\
\hline & Address & 100069, Beijing, People’s Republic of China \\
\hline & Division & College of Life Science \\
\hline & Organization & Graduate University of Chinese Academy of Sciences \\
\hline & Address & 100049, Beijing, People's Republic of China \\
\hline & Division & $\begin{array}{l}\text { Systems and Intervention Research Centre for Health, School of Medical } \\
\text { Sciences }\end{array}$ \\
\hline & Organization & Edith Cowan University \\
\hline & Address & 6027, Perth, WA, Australia \\
\hline & Division & \\
\hline & Organization & \\
\hline & Address & \\
\hline & Email & wei.wang@ecu.edu.au \\
\hline \multirow[t]{3}{*}{ Author } & Family Name & $\mathbf{W u}$ \\
\hline & Particle & \\
\hline & Given Name & Jingjing \\
\hline
\end{tabular}


Suffix

Division

Organization

Address

Division

Organization

Address

Email

\begin{tabular}{|c|c|c|}
\hline & Email & \\
\hline \multirow[t]{14}{*}{ Author } & Family Name & Zhang \\
\hline & Particle & \\
\hline & Given Name & Jie \\
\hline & Suffix & \\
\hline & Division & Department of Epidemiology and Biostatistics, School of Public Health \\
\hline & Organization & Capital Medical University \\
\hline & Address & 100069, Beijing, People's Republic of China \\
\hline & Division & \\
\hline & Organization & Beijing Municipal Key Laboratory of Clinical Epidemiology \\
\hline & Address & 100069, Beijing, People's Republic of China \\
\hline & Division & \\
\hline & Organization & \\
\hline & Address & \\
\hline & Email & \\
\hline \multirow[t]{8}{*}{ Author } & Family Name & Dai \\
\hline & Particle & \\
\hline & Given Name & Ying \\
\hline & Suffix & \\
\hline & Division & Faculty of Medicine \\
\hline & Organization & The University of Hong Kong \\
\hline & Address & Hong Kong, People's Republic of China \\
\hline & Email & \\
\hline \multirow[t]{8}{*}{ Author } & Family Name & Bian \\
\hline & Particle & \\
\hline & Given Name & Lili \\
\hline & Suffix & \\
\hline & Division & \\
\hline & Organization & Yuetan Community Health Service Center Affiliated to Fuxing Hospital \\
\hline & Address & 100045, Beijing, People's Republic of China \\
\hline & Email & \\
\hline \multirow[t]{7}{*}{ Author } & Family Name & Song \\
\hline & Particle & \\
\hline & Given Name & Manshu \\
\hline & Suffix & \\
\hline & Division & Department of Epidemiology and Biostatistics, School of Public Health \\
\hline & Organization & Capital Medical University \\
\hline & Address & 100069, Beijing, People's Republic of China \\
\hline
\end{tabular}

Department of Epidemiology and Biostatistics, School of Public Health Capital Medical University

100069, Beijing, People's Republic of China

Beijing Municipal Key Laboratory of Clinical Epidemiology

100069, Beijing, People's Republic of China 
Division

Organization Beijing Municipal Key Laboratory of Clinical Epidemiology

Address 100069, Beijing, People's Republic of China

Email

\begin{tabular}{ll}
\hline Author & Family Name \\
Particle & Russell \\
Given Name & Alyce \\
Suffix & \\
Division & Systems and Intervention Research Centre for Health, School of Medical \\
Organization & Sciences \\
Address & Edith Cowan University \\
Email & 6027, Perth, WA, Australia \\
\hline
\end{tabular}

Received

12 January 2013

Schedule Revised

Accepted 14 September 2013

Abstract To investigate the association of tag-SNPs and haplotype structures of the CIDEA gene with obesity in a Han Chinese population. Five single nucleotide polymorphisms (SNPs) (rs1154588/V115F, rs4796955/SNP1, rs8092502/SNP2, rs12962340/SNP3 and rs7230480/SNP4) in the CIDEA gene were genotyped in a casecontrol study. Genotyping was performed using the sequenom matrix-assisted laser desorption/ionization time-of-flight mass spectrometry iPLEX platform. There were significant differences between the obese and control groups in genotype distributions of V115F $(P<0.001)$, SNP1 $(P=0.006)$ and SNP2 $(P=0.005)$.

Carriers of V115F-TT, SNP1-GG and SNP2-CC genotypes had a 2.84-fold (95\% CI 1.73-4.66), 2.19-fold (95\% CI 1.09-4.38) and 4.37-fold (95\% CI 1.21-15.08) increased risk for obesity, respectively. Haplotype analysis showed that GTTC (SNP1/SNP2/V115F/SNP4) had 1.41-fold (95\% CI 1.02-1.95) increased risk for obesity; whereas, haplotype TTGC had 0.48-fold (95\% CI 0.24-0.96) decreased risk for obesity. Using the multifactor dimensionality reduction method, the best model including SNP1, SNP2, V115F and SNP4 polymorphisms was identified with a maximum testing accuracy to $59.32 \%$ and a perfect cross-validation consistency of $10 / 10(P=0.011)$. Logistic analysis indicated that there was a significant interaction between SNP1 and V115F associated with obesity. Subjects having both genotypes of SNP1/GG and V115F/TT were more susceptible to obesity in the Han Chinese population (OR 2.66, 95 \%: 1.22-5.80). Genotypes of V115F/ TT, SNP1/GG and SNP2/CC and haplotype GTTC of CIDEA gene were identified as risk factors for obesity in the Han Chinese population. The interaction between SNP1 and V115F could play a joint role in the development of obesity.

Keywords (separated by '-') Chinese - Association study - Obesity - CIDEA - Polymorphism - Haplotype 
3 The genetic contribution of $C I D E A$ polymorphisms, haplotypes

\section{and loci interaction to obesity in a Han Chinese population}

\author{
Jingjing Wu $\cdot$ Ling Zhang $\cdot$ Jie Zhang $\cdot$ \\ Ying Dai $\cdot$ Lili Bian · Manshu Song • \\ Alyce Russell $\cdot$ Wei Wang
}

Received: 12 January 2013/ Accepted: 14 September 2013

(C) Springer Science+Business Media Dordrecht 2013 and SNP2 $(P=0.005)$. Carriers of V115F-TT, SNP1-GG and SNP2-CC genotypes had a 2.84-fold (95\% CI 1.73-4.66), 2.19-fold (95\% CI 1.09-4.38) and 4.37-fold (95\% CI 1.21-15.08) increased risk for obesity, respectively. Haplotype analysis showed that GTTC (SNP1/ SNP2/V115F/SNP4) had 1.41-fold (95\% CI 1.02-1.95) increased risk for obesity; whereas, haplotype TTGC had 0.48-fold (95\% CI 0.24-0.96) decreased risk for obesity. Using the multifactor dimensionality reduction method, the best model including SNP1, SNP2, V115F and SNP4 polymorphisms was identified with a maximum testing accuracy to $59.32 \%$ and a perfect cross-validation consistency of $10 / 10(P=0.011)$. Logistic analysis indicated that there was a significant interaction between SNP1 and V115F associated with obesity. Subjects having both genotypes of SNP1/GG and V115F/TT were more susceptible to obesity in the Han Chinese population (OR 2.66, $95 \%$ : 1.22-5.80). Genotypes of V115F/TT, SNP1/ GG and SNP2/CC and haplotype GTTC of CIDEA gene were identified as risk factors for obesity in the Han Chinese population. The interaction between SNP1 and V115F could play a joint role in the development of obesity.

Keywords Chinese - Association study - Obesity · CIDEA · Polymorphism · Haplotype

\section{Introduction}

Obesity, largely developed from the imbalance between energy intake and expenditure, manifests as excessive total body fat. It is a result of the interaction between environmental factors and genetic loads. It has been demonstrated in twins and familial studies that genetic contributions exist $[1,2]$. Linkage and association studies indicate that cell

China

\begin{tabular}{|l|lll|}
\hline Journal : Large $\mathbf{1 1 0 3 3}$ & Dispatch : $\mathbf{1 8 - 9 - 2 0 1 3}$ & Pages : 9 \\
Article No. : $\mathbf{2 6 7 1}$ & $\square$ LE & $\square$ TYPESET \\
& MS Code : MOLE-6442 & $\sim_{\mathrm{CP}}$ & $\checkmark$ DISK \\
\hline
\end{tabular}


death-inducing DNA fragmentation factor alpha-like effector A (CIDEA) is a candidate gene for the development of obesity [3-5].

The CIDEA gene (18p11.12) is $23.22 \mathrm{~kb}$ in length with five exons and four introns. It was identified by virtue of its sequence homology to the N-terminal region of the apoptotic DNA fragmentation factor Dff40/CAD and Dff45/ ICAD [6]. CIDEA protein is a member of the cell deathinducing DNA fragmentation factor alpha-like effector (CIDE) protein family. CIDEA is highly expressed in brown adipose tissue (BAT) of rodents and white adipose tissue (WAT) of humans, and is associated with the development of obesity in both rodents [7] and humans [8]. CIDEA-null mice show lean phenotypes with increased metabolic rate and lipolysis in BAT, and are resistant to diet-induced obesity and diabetes mellitus [7]. In humans, CIDEA expression is associated with a decrease in body mass index (BMI), waist measurement, waist-to-hip ratio (WHR) and basal metabolic rate [8]. It has also been suggested that CIDEA expression may cross-talk with tumor necrosis factor- $\alpha$ (TNF- $\alpha$ ). TNF- $\alpha$ down-regulates CIDEA expression and at the same time stimulates basal lipolysis in human fat cells [9].

Association studies on CIDEA gene focused on the V115F (rs11545881) single nucleotide polymorphism (SNP), which is a non-synonymous SNP in exon 4 that results in an amino acid substitution (V115F). A study showed that the V115F polymorphism was associated with BMI both in males $(P=0.023)$ and females $(P=0.021)$, and $\mathrm{G}$ allele was a risk allele (OR 1.32, $95 \% \mathrm{CI}$ 1.03-1.69) in a Swedish population [10]. However, our previous research in both Japanese [11] and Chinese populations [12] have shown that the $\mathrm{T}$ allele may serve as a risk factor for metabolic syndrome and its related phenotypes.

In this study, we genotyped V115F (rs11545881) in another Chinese sample to validate this risk allele for obesity, and further selected another four tag-SNPs in the CIDEA gene (rs4796955/SNP1, rs8092502/SNP2, rs12962340/ SNP3, and rs7230480/SNP4). This was done to investigate a possible interaction between the effects of SNPs and haplotypes of the CIDEA gene on obesity in Han Chinese.

\section{Materials and methods}

\section{Subjects}

This present study was a part of the National High Technology Research and Development Program-863 of China, a population-based cross-sectional survey on relative risk factors of chronic non-communicable diseases (NCD) in the Chinese population during a 2-year period of
2007-2008. We selected 309 obese and 433 controls from the 3,000 participants of this nation-wide study and matched on age, gender and residence. An individual was defined as being obese if they had a BMI of $28 \mathrm{~kg} / \mathrm{m}^{2}$ or more, according to the recommended standard by the Cooperative Meta-analysis Group of Working Group on Obesity in China [13]. We excluded from this study individuals with the following: (1) physician-diagnosed diabetes mellitus, coronary heart disease, myocardial infarction, stroke, cancer, severe kidney or liver diseases; (2) infectious diseases; (3) secondary obesity caused by other reasons; and (4) Cushing Syndrome.

All of the participants signed informed consents before participating in this study, with approval been granted by the Ethical Committee, Capital Medical University, Beijing, China.

Measurement of anthropometric parameters

Following an interview by questionnaire, which covered demographic characteristics, residential history, socioeconomic status, personal behavior and medical history, all participants were asked to fast overnight before having a physical examination. Body weight, height, waist circumference (WC), hip circumference (HC), systolic blood pressure (SBP) and diastolic blood pressure (DBP) were measured by well-trained community doctors. Each measurement was performed three times and the average value was calculated as a final reading. Height and weight were measured to the nearest $0.1 \mathrm{~kg}$ and $0.1 \mathrm{~cm}$ respectively, with participants wearing light indoor clothing without shoes. BMI was calculated as weight in kilograms divided by height in meters squared $\left(\mathrm{kg} / \mathrm{m}^{2}\right)$. After inhalation and exhalation, WC was obtained at the midpoint between the lowest rib and the iliac crest to the nearest $0.1 \mathrm{~cm}$, while the subject stood upright, with arms hanging freely and feet together. $\mathrm{HC}$ was measured over nonrestrictive underwear or light-weight shorts at the level of the maximum extension of the buttocks in a horizontal level, without compressing the skin. WHR was calculated as WC divided by HC. Blood pressure was measured by mercury sphygmomanometer on the right arm of the participant in a comfortable sitting position after at least a $15 \mathrm{~min}$ rest.

Finger capillary blood collection and DNA preparation

Finger capillary blood was collected in the morning after an overnight fasting, and stored on 903 specimen collection paper (Kent, UK). The saver card has a sample collection area of five $1.3 \mathrm{~cm}$ circles with each circle holding 75-80 $\mu \mathrm{L}$ of sample. Paper samples were air dried overnight, then individually placed in plastic bags with desiccants and stored at $-20{ }^{\circ} \mathrm{C}$. 144

\begin{tabular}{|l|lll|}
\hline Journal : Large 11033 & Dispatch : $\mathbf{1 8 - 9 - 2 0 1 3}$ & Pages : 9 \\
Article No. : $\mathbf{2 6 7 1}$ & $\square$ LE & $\square$ TYPESET \\
MS Code : MOLE-6442 & $\sim_{\mathrm{CP}}$ & $\checkmark$ DISK \\
\hline
\end{tabular}


Whole-genome DNA was extracted by the Chelex-100 extraction method [14]. Firstly, a piece of $3 \mathrm{~mm} \times 3 \mathrm{~mm}$ dried blood stain was cut down and put into a $1.5 \mathrm{~mL}$ centrifuge tube. Then $1 \mathrm{~mL} \mathrm{ddH}_{2} \mathrm{O}$ was added, the tube was shaken for $10 \mathrm{~s}$ and placed at room temperature for half an hour. After centrifugation for $3 \mathrm{~min}$ at $12,500 \times \mathrm{g}$, the majority of the supernatant liquid was removed and $200 \mu \mathrm{L}$ of freshly prepared $5 \%$ (w/v) Chelex-100 was added into the tube. The sample was mixed for $10 \mathrm{~s}$ and followed by centrifugation for $3 \mathrm{~min}$ at $12,500 \times g$ again. The sample was then incubated at $56{ }^{\circ} \mathrm{C}$ for $30 \mathrm{~min}$, followed by $100{ }^{\circ} \mathrm{C}$ for $8 \mathrm{~min}$. Finally, centrifugation for $3 \mathrm{~min}$ at $13,000 \times g$ was performed. The supernatant liquid containing DNA was stored at $4{ }^{\circ} \mathrm{C}$ for amplification.

\section{Tag-SNP selection}

We downloaded Han Chinese population SNP data from the database of the international HapMap Project (HapMap Data Rel 24/phase II Nov08, on NVBI B36 assembly, dbSNP b126). Using Haploview 4.0 software, we selected five tag-SNPs of the CIDEA gene (SNP/V115F: rs11545881, SNP1: rs4796955, SNP2: rs8092502, SNP3: rs12962340, and SNP4: rs7230480) which had a minor allele frequency (MAF) $\geq 5 \%$ in Han Beijing Chinese. Among the SNPs whose $r^{2} \geq 0.8$, we selected the one with highest MAF for genotyping. Figure 1a shows the detailed information of the selected tag-SNPs of the CIDEA gene.

SNP genotyping

A combined approach utilizing nested polymerase chain reaction (PCR) and pyrosequencing technology (PSQ 96MA, BIOTAGE, Sweden) was used for V115F

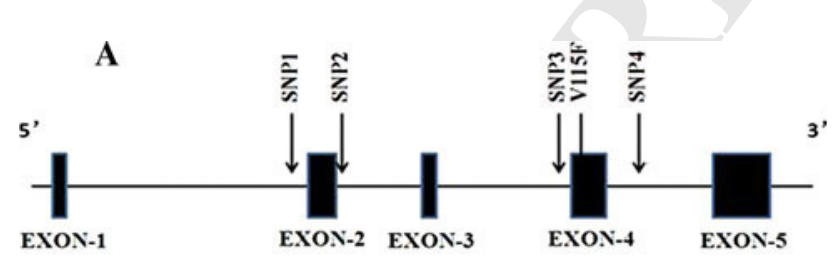

B

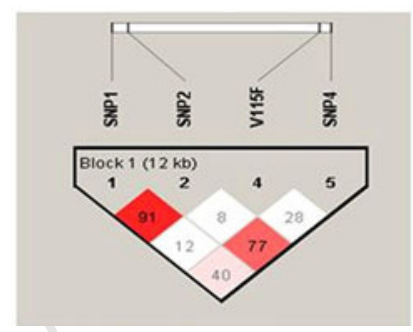

Fig. 1 a The location of the tag-SNPs in the CIDEA gene. The exons were indicated by black boxes. $b$ LD plot among five tag-SNPs of CIDEA gene genotyping. The nested PCR primers were designed as followed: the outside primers were $5^{\prime}$-CTGGCATAAGAGCA GAGTG-3' (forward) and 5'-GAGCCTGTGGGATAAG AGT- $3^{\prime}$ (reverse), and the inner primers were $5^{\prime}$-GGT TAGGAAGGCTCCTGA-3' (forward) and 5'-GATGTCG TAGGACACGGAGTA- $3^{\prime}$ (reverse). The pyrosequencing primers were $5^{\prime}$-CAGGGCAGCCAGCAC- $3^{\prime}$. The firststage PCR was executed in a $20 \mu \mathrm{L}$ volume containing $2 \mu \mathrm{L}$ $10 \times$ PCR buffer (including $\left.\mathrm{MgCl}_{2}\right), 2 \mu \mathrm{L} \mathrm{dNTPs}(2.5 \mathrm{mM}$ ), $0.2 \mu \mathrm{L}$ forward $\operatorname{primer}(20 \mu \mathrm{M}), 0.2 \mu \mathrm{L}$ reverse pri$\operatorname{mer}(20 \mu \mathrm{M}), 4 \mu \mathrm{L}$ genomic DNA $(25 \mathrm{ng} / \mu \mathrm{L}), 0.08 \mu \mathrm{L}$ Taq polymerase ( $5 \mathrm{U} / \mu \mathrm{L}$, Takara, Japan), and $11.52 \mu \mathrm{L}$ deionized $\mathrm{H}_{2} \mathrm{O}$. The second-stage PCR was executed in a $55 \mu \mathrm{L}$ volume containing $5.5 \mu \mathrm{L} 10 \times$ PCR buffer (including $\left.\mathrm{MgCl}_{2}\right), 5.5 \mu \mathrm{L}$ dNTPs $(2.5 \mathrm{mM}), 0.55 \mu \mathrm{L}$ forward primer $(20 \mu \mathrm{M}), 0.55 \mu \mathrm{L}$ reverse primer $(20 \mu \mathrm{M}), 3 \mu \mathrm{L}$ DNA (the production of the first-stage PCR), $0.22 \mu \mathrm{L} \mathrm{Taq}$ polymerase (5 U/ $\mu \mathrm{L}$, Takara, Japan) and $39.68 \mu \mathrm{L}$ deionized $\mathrm{H}_{2} \mathrm{O}$. PCRs were initiated by denaturation at $95{ }^{\circ} \mathrm{C}$ for $5 \mathrm{~min}$, followed by 35 cycles of; $30 \mathrm{~s}$ at $94{ }^{\circ} \mathrm{C}, 30 \mathrm{~s}$ at $57^{\circ} \mathrm{C}$, and $60 \mathrm{~s}$ at $72{ }^{\circ} \mathrm{C}$, with the PCR products prolonged for $10 \mathrm{~min}$ at $72{ }^{\circ} \mathrm{C}$ in the final cycle and finally held at $4{ }^{\circ} \mathrm{C}$.

The genotyping of the other four tag-SNPs (SNP1: rs4796955, SNP2: rs8092502, SNP3: rs12962340 and SNP4: rs7230480) was performed using the sequenom matrix-assisted laser desorption/ionization time-of-flight (MALDI-TOF) mass spectrometry (MS) iPLEX platform [15]. This technique is a high-throughput MS method for detecting SNPs. According to the manufacturers' instructions, the whole process includes: multiplex PCR amplification, shrimp alkaline phosphatase treatment, iPLEX primer extension, clean resin, MALDI-TOF MS analysis and data analysis [16, 17].

We randomly selected 30 samples from the participants to validate the genotyping results of all the five SNPs using another genotyping method, i.e., Sanger dideoxy method to confirm the identity.

Statistical analysis

Each polymorphism was evaluated for Hardy-Weinberg equilibrium by online software (http://ihg2.helmholtzmuenchen.de/cgi-bin/hw/hwa1.pl). $P \geq 0.01$ was considered to obey the Hardy-Weinberg equilibrium. The distributions of allelic and genotypic frequencies were analyzed using $\chi^{2}$ test. The single locus association between a polymorphism and obesity was estimated by multiple logistic regression analysis, with age and gender adjusted. For continuous variables with normal distribution, we used ANOVA to detect the difference of distribution between the different genotypes. The variables which were non-normal distributions were analyzed via rank sum test. The statistical analyses were carried out

\begin{tabular}{|l|lll|} 
Journal : Large $\mathbf{1 1 0 3 3}$ & Dispatch : $\mathbf{1 8 - 9 - 2 0 1 3}$ & Pages : 9 \\
Article No. : $\mathbf{2 6 7 1}$ & $\square$ LE & $\square$ TYPESET \\
MS Code : MOLE-6442 & $\sim_{\text {CP }}$ & $\checkmark$ DISK \\
\hline
\end{tabular}


using SPSS version 19.0 for Windows (SPSS Inc., Chicago, IL, USA). The frequencies of the haplotypes and association analyses were completed by Haploview software (version 4.0; Mark Daly's Laboratory, Broad Institute; http://sourceforge.net/projects/haploview/) [18]. We analyzed the presence of interactions associated with obesity susceptibility between the tag-SNPs by multifactor dimensionality reduction method (MDR) (version 1.1.0; Computational Genetics Laboratory, Dartmouth Medical School, Lebanon, NH; www.epistasis.org) and logistic regression. The MDR method is nonparametric and modelfree, which is directly applicable to case-control studies to detect the interaction between gene-gene and gene-environment. The best MDR model is determined to have a $P$ value $<0.05$, a maximum testing accuracy and a high cross-validation consistency (CVC) [19]. Probability values presented were for two-tailed tests and $P<0.05$ was considered statistically significant.

\section{Results}

V115F polymorphism of CIDEA gene and obesity

$\mathrm{V} 115 \mathrm{~F}(\mathrm{G} / \mathrm{T})$ was genotyped in 742 participants (309 obese vs. 433 controls), with the basal demographic and clinical characteristics of these participants summarized in Table 1 . The obese group had significantly higher levels of BMI, SBP, DBP, WC, HC and WHR compared to the control group. No significant differences were found in age and gender among the two groups (Table 1).

V115F genotypic frequencies for the GG, GT and TT were $19.54,59.70$, and $20.75 \%$, respectively. The allelic frequencies of $\mathrm{G}$ and $\mathrm{T}$ alleles were 49.39 and $50.61 \%$, respectively. The genotypic distribution of the $\mathrm{V} 115 \mathrm{~F}$ followed Hardy-Weinberg equilibrium in the controls $(P=0.011)$. The frequency of the TT genotype was significantly higher in the obese group compared to the control group (23.62 vs. $18.71 \%, P<0.001)$ (Table 2). Multiple logistic regression analysis (age and gender adjusted) identified that participants with the TT genotype were 2.84-fold at risk (95\% CI 1.73-4.66, $P<0.001$ ) and those with the GT genotype were 2.63-fold at risk (95\% CI $1.72-4.01, P<0.001$ ) for obesity when compared to those with the GG genotype. Meanwhile, $\chi^{2}$ analysis results showed that participants with the $\mathrm{T}$ allele were 1.46-fold (95\% CI 1.19-1.80, $P<0.001$ ) at risk for obesity when compared to those with the G allele.

In genotypic model (GG vs.GT vs.TT), we found that the average BMI, WC, HC and WHR measurements were highest in patients with the TT genotype followed by GT and GG. In the dominant model (TT vs. TG + GG), we found that these obesity related levels were significantly

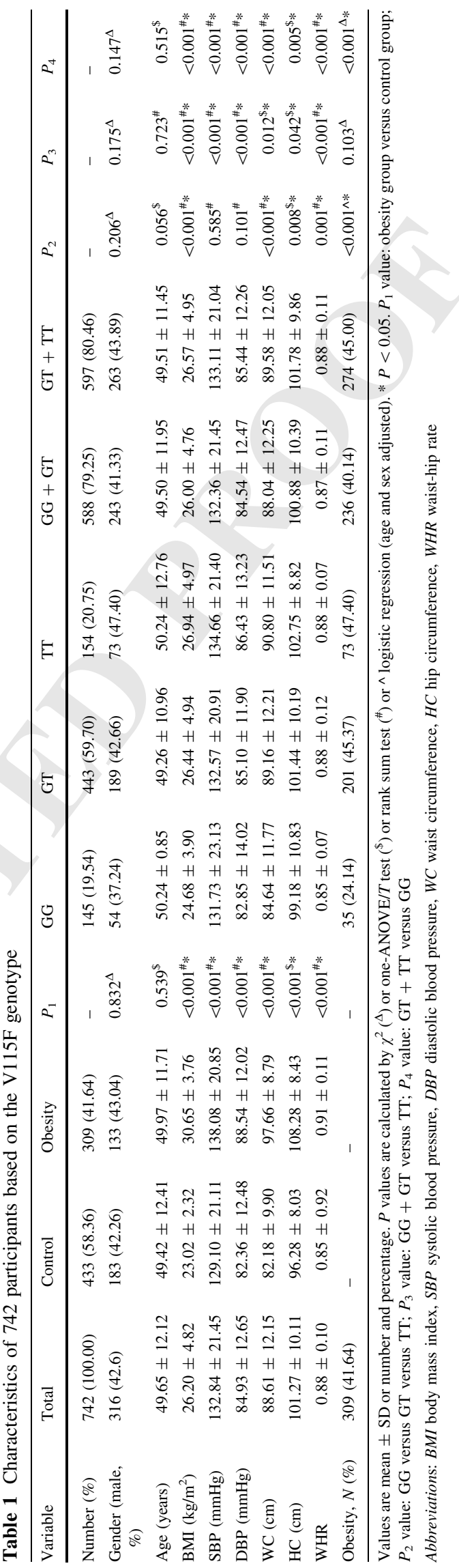

\begin{tabular}{|l|lll|}
\hline & Journal : Large 11033 & Dispatch : 18-9-2013 & Pages : 9 \\
Article No : $\mathbf{2 6 7 1}$ & $\square_{\mathrm{CE}}$ & $\square_{\mathrm{CP}}^{\mathrm{TY}}$ & $\boldsymbol{\sim}_{\text {DISK }}$ \\
\hline
\end{tabular}


Table 2 Multiple logistic regression analysis of associations between the CIDEA genotypes and obesity

\begin{tabular}{|c|c|c|c|c|c|c|}
\hline SNPs & Polymorphism & Control $^{\mathrm{a}}$ & Obesity $^{a}$ & $P$ value $^{\mathrm{b}}$ & OR & $95 \% \mathrm{CI}$ \\
\hline \multirow[t]{7}{*}{ SNP1 } & Genotype & & & $0.006^{*}$ & & \\
\hline & GG & 46 (26.59) & $68(43.31)$ & $0.027 *$ & 2.19 & $1.09-4.38$ \\
\hline & GT & 99 (57.23) & 70 (44.59) & 0.903 & 1.04 & $0.54-2.02$ \\
\hline & $\mathrm{TT}$ & $28(16.18)$ & $19(12.10)$ & - & 1.00 & - \\
\hline & Allele & & & & & \\
\hline & G & $191(55.20)$ & $206(65.61)$ & $0.006^{\Delta_{*}}$ & 1.55 & $1.13-2.12$ \\
\hline & $\mathrm{T}$ & $155(44.80)$ & $108(34.39)$ & & & \\
\hline \multirow[t]{7}{*}{ SNP2 } & Genotype & & & $0.005^{*}$ & & \\
\hline & $\mathrm{CC}$ & $3(1.73)$ & $13(8.39)$ & $0.025^{*}$ & 4.37 & $1.21-15.80$ \\
\hline & $\mathrm{TC}$ & $62(35.84)$ & $36(23.23)$ & $0.035^{*}$ & 0.59 & $0.04-0.96$ \\
\hline & TT & $108(62.43)$ & $106(68.39)$ & - & 1.00 & - \\
\hline & Allele & & & & & \\
\hline & $\mathrm{C}$ & $68(19.65)$ & $62(20.00)$ & $0.911^{\Delta}$ & 1.02 & $0.70-1.50$ \\
\hline & $\mathrm{T}$ & $278(80.35)$ & $248(80.00)$ & & & \\
\hline \multirow[t]{7}{*}{ SNP3 } & Genotype & & & 0.367 & & \\
\hline & TT & 91 (81.98) & 76 (88.37) & 0.811 & 1.16 & $0.35-3.80$ \\
\hline & TA & 13 (11.71) & $5(5.81)$ & 0.424 & 0.53 & $0.11-2.50$ \\
\hline & AA & $7(6.31)$ & $5(5.81)$ & - & 1.00 & - \\
\hline & Allele & & & & & \\
\hline & $\mathrm{T}$ & $195(87.84)$ & 157 (91.28) & $0.272^{\Delta}$ & 1.45 & $0.75-2.82$ \\
\hline & A & 27 (12.16) & $15(8.72)$ & & & \\
\hline \multirow[t]{7}{*}{ SNP4 } & Genotype & & & 0.968 & & \\
\hline & $\mathrm{CC}$ & $128(73.99)$ & 117 (74.52) & 0.799 & 1.22 & $0.26-5.67$ \\
\hline & $\mathrm{CT}$ & $41(23.7)$ & 37 (23.57) & 0.810 & 1.21 & $0.25-5.86$ \\
\hline & TT & $4(2.31)$ & $3(1.91)$ & - & 1.00 & - \\
\hline & Allele & & $y$ & & & \\
\hline & $\mathrm{C}$ & $297(85.84)$ & $271(86.31)$ & $0.862^{\Delta}$ & 1.04 & $0.670-1.62$ \\
\hline & $\mathrm{T}$ & $49(14.16)$ & $43(13.69)$ & & & \\
\hline \multirow[t]{7}{*}{ V115F } & Genotype & & & $<0.001 *$ & & \\
\hline & $\mathrm{TT}$ & $81(18.71)$ & $73(23.62)$ & $<0.001 *$ & 2.84 & $1.73-4.66$ \\
\hline & GT & $242(55.89)$ & $201(65.05)$ & $<0.001 *$ & 2.63 & $1.72-4.01$ \\
\hline & GG & $110(25.40)$ & $35(11.33)$ & - & 1.00 & - \\
\hline & Allele & & & & & \\
\hline & $\mathrm{T}$ & 404 (46.65) & $347(56.15)$ & $<0.001^{\Delta *}$ & 1.46 & $1.19-1.80$ \\
\hline & G & $462(53.35)$ & $271(43.85)$ & & & \\
\hline \multirow[t]{4}{*}{ Combined genotypes } & & & & $<0.001 *$ & & \\
\hline & 0-risk & $106(61.27)$ & $61(38.85)$ & - & 1.00 & - \\
\hline & 1-risk & $56(32.37)$ & $72(45.68)$ & $0.001 *$ & 2.23 & $1.40-3.58$ \\
\hline & 2-risk & $11(63.58)$ & $24(15.29)$ & $0.001 *$ & 3.79 & $1.74-8.28$ \\
\hline
\end{tabular}

OR odd ratio, $95 \%$ CI $95 \%$ confidence interval

* $P<0.05$

${ }^{\text {a }}$ Numbers are frequencies and percentage

${ }^{\mathrm{b}} P$ value was calculated by $\chi^{2}$ test $\left(^{\Delta}\right)$ or multiple logistic regression (age and sex adjusted)

281 higher in TT group than those in GG + GT group (BMI, $282 \quad P<0.001 ;$ SBP, $P<0.001 ;$ DBP, $P<0.001$; WC, $283 \quad P=0.012$; HC, $P=0.042$; WHR, $P<0.001$, respectively) 284 differences of these levels were significantly higher in $\mathrm{GT}+\mathrm{TT}$ group compared to the GG group as expected (BMI, $P<0.001$; SBP, $P<0.001$; DBP, $P<0.001$; WC, $P<0.001$; HC, $P=0.005$, WHR, $P<0.001$, respectively)
285

\begin{tabular}{|l|ll|} 
Journal : Large 11033 & Dispatch : 18-9-2013 & Pages : 9 \\
Article No. : $\mathbf{2 6 7 1}$ & $\square$ LE & $\square$ TYPESET \\
MS Code : MOLE-6442 & $\checkmark$ CP & $\checkmark$ DISK \\
\hline
\end{tabular}


(Table 1). The distribution of the two genotype frequencies were significantly different between the obese and controls $(P<0.001)$.

Association between the other four tag-SNPs and obesity

We genotyped another four selected CIDEA tag-SNPs (SNP1 G/T, SNP2 T/C, SNP3 T/A, SNP4 C/T) in 330 participants (obese/controls $=157 / 173$ ). Distributions of the genotypes and alleles of the four SNPs are listed in Table 2. Analysis showed that the controls were in HardyWeinberg equilibrium at SNP1 $(P=0.039)$, SNP2 $(P=0.076)$ and SNP4 $(P=0.740)$, while the genotypic distribution of SNP3 did not follow Hardy-Weinberg equilibrium $(P<0.001)$, so SNP3 was excluded from further analysis. The MAF of these SNPs (SNP1T, SNP2C and SNP4T) were 44.80, 19.65 and $14.17 \%$ in controls, respectively (Table 2). These were consistent with the MAF of Han Chinese in Beijing, China (http://www.ncbi. nlm.nih.gov/pubmed). Multiple logistic regression analysis (adjusted by age and gender) indicated that both SNP1 and SNP2 polymorphisms were significantly associated with obesity $(P=0.006$ and 0.005 , respectively) (Table 2$)$. SNP1/GG and SNP2/CC genotypes were more frequent in the obese group compared to the control group $(P=0.027$, 0.025 , respectively).

The analysis results of SNP1 showed overall that WC and BMI levels in the GG genotype $(\mathrm{WC}=90.31 \pm 10.91 \mathrm{~cm}$; $\mathrm{BMI}=27.08 \pm 4.24 \mathrm{~kg} / \mathrm{m}^{2}$ ) were significantly higher compared to any other two genotypes (GT: WC $=86.06 \pm$ $12.00 \mathrm{~cm}, P=0.030 ;$ BMI $=25.45 \pm 4.45 \mathrm{~kg} / \mathrm{m}^{2}, P=$ 0.030 ; TT: $\mathrm{WC}=85.94 \pm 11.36 \mathrm{~cm}, P=0.002 ; \mathrm{BMI}=$ $25.41 \pm 4.43 \mathrm{~kg} / \mathrm{m}^{2}, P=0.028$ ), suggesting that participants with the GG genotype were more susceptible to obesity. Multiple logistic regression (adjusted for age and gender) analysis revealed that when compared with the TT genotype, participants carrying the GG genotype had a 2.19fold (95\% CI 1.09-4.38, $P=0.027)$ risk of obesity, and when compared with the $\mathrm{T}$ allele, participants with the $\mathrm{G}$ allele had a 1.55 -fold (95 \% CI 1.13-2.12, $P=0.006$ ) risk of obesity. All of these results indicated that the variant $G$ allele of SNP1 was the risk allele of obesity.

The analysis results of SNP2 showed that WC levels were higher based on genotypes of CT $(84.55 \pm 11.62 \mathrm{~cm})<$ TT $(88.31 \pm 11.32 \mathrm{~cm})<\mathrm{CC}(92.75 \pm 11.70 \mathrm{~cm})$, and there was a statistically significant difference between the three genotypes $(P=0.005)$. Logistic regression analysis of SNP2 showed that when compared with the TT genotype, participants with the CC genotype had a 4.37-fold (95\% CI $1.21-15.80, P=0.025)$ risk, while the $\mathrm{CT}$ genotype was lower with a 0.59 -fold (95 \% CI 0.04-0.96, $P=0.035$ ) risk of obesity. No significant difference was detected in the BMI according to the genotypes.

Haplotypes analysis of the selected tag-SNPs of CIDEA gene

When we combined the four tag-SNPs and inferred haplotypes using Haploview 4.0 software, ten possible haplotypes were derived from the observed genotypes (SNP1/SNP2/ V115F/SNP4) (Fig. 1b). Six haplotypes with frequencies above $5 \%$ were haplotype 1 (H1)-GTTC $(33.5 \%)$, H2GTGC (20.7\%), H3-TCGC (9.4\%), H4-TCTC (8.9\%), H5-TTTC $(6.7 \%)$ and H6-TTGC (6.0 \%) (Table 3). H1 was more common in the obese participants (37.55\%) compared to the controls ( $29.91 \%, P=0.039$ ), while $\mathrm{H} 6$ was common in the controls $(7.92 \%)$ compared to the obese $(3.98 \%$, $P=0.034)$. The risk of obesity was significantly increased among the participants carrying haplotype H1 (OR 1.41, $95 \%$ CI 1.02-1.95), and decreased among participants with haplotype H6 (OR 0.48, $95 \%$ CI 0.24-0.96).

Interaction analysis of CIDEA gene tag-SNPs on obesity

Assuming a combined model (i.e. homozygous risk genotypes vs. the combining group of the other two genotypes),
357

358

359 360

Table 3 Frequencies of the haplotypes based on the tag-SNPs in obese and controls

\begin{tabular}{|c|c|c|c|c|c|c|c|c|c|c|c|}
\hline \multirow[t]{2}{*}{ Haplotypes } & \multicolumn{4}{|c|}{ Genotype } & \multirow[t]{2}{*}{ Freq. } & \multirow{2}{*}{$\begin{array}{l}\text { Obesity } \\
n(\%)\end{array}$} & \multirow{2}{*}{$\begin{array}{l}\text { Control } \\
n(\%)\end{array}$} & \multirow[t]{2}{*}{$\chi^{2}$ value } & \multirow[t]{2}{*}{$P$ value } & \multirow[t]{2}{*}{ OR } & \multirow[t]{2}{*}{$95 \% \mathrm{CI}$} \\
\hline & SNP1 & SNP2 & V115F & SNP4 & & & & & & & \\
\hline H1 & G & $\mathrm{T}$ & $\mathrm{T}$ & $\mathrm{C}$ & 0.335 & 117.9 (37.55) & $103.5(29.91)$ & 4.28 & $0.039^{*}$ & 1.41 & $1.02-1.95$ \\
\hline $\mathrm{H} 2$ & G & $\mathrm{T}$ & G & $\mathrm{C}$ & 0.207 & 65.9 (20.99) & 70.8 (20.46) & 0.03 & 0.869 & 1.03 & $0.71-1.51$ \\
\hline $\mathrm{H} 3$ & $\mathrm{~T}$ & $\mathrm{C}$ & G & $\mathrm{C}$ & 0.094 & $26.4(8.41)$ & $35.4(10.23)$ & 0.64 & 0.425 & 0.81 & $0.48-1.37$ \\
\hline $\mathrm{H} 4$ & & $\mathrm{C}$ & $\mathrm{T}$ & $\mathrm{C}$ & 0.089 & $31.1(9.90)$ & $27.8(8.03)$ & 0.71 & 0.401 & 1.26 & $0.74-2.15$ \\
\hline H5 & $\mathrm{T}$ & $\mathrm{T}$ & $\mathrm{T}$ & $\mathrm{C}$ & 0.067 & $15.5(4.94)$ & $28.5(8.24)$ & 2.9 & 0.088 & 0.58 & $0.31-1.10$ \\
\hline H6 & $\mathrm{T}$ & $\mathrm{T}$ & G & $\mathrm{C}$ & 0.060 & $12.5(3.98)$ & $27.4(7.92)$ & 4.51 & $0.034 *$ & 0.48 & $0.24-0.96$ \\
\hline
\end{tabular}

OR odd ratio, $95 \%$ CI $95 \%$ confidence interval

$* P<0.05$

\begin{tabular}{|l|lll|}
\hline & Journal : Large 11033 & Dispatch : 18-9-2013 & Pages : 9 \\
Article No. : 2671 & $\square$ & $\square$ TYPESET \\
MS Code : MOLE-6442 & $\checkmark_{\mathrm{CP}}$ & $\checkmark$ DISK \\
\hline
\end{tabular}


we did combined analyses for the three SNPs which were significantly associated with obesity in the previous single locus analysis; SNP1 (GG vs. GT + TT); SNP2 (CC vs. $\mathrm{CT}+\mathrm{TT}$ ); V115F (TT vs. GT + GG). Compared with those carrying genotypes of SNP1/GT $+\mathrm{TT}, \mathrm{SNP} 2 /$ $\mathrm{CT}+\mathrm{TT}$ and V115F/GT + GG, participants carrying only one of the three homozygous risk genotypes (SNP1/ GG or SNP2/CC or V115F/TT) were associated with a 2.23 -fold (95 \% CI 1.40-3.58, $P=0.001$ ) increased risk to obesity, while the risk was statistically increased to 3.79fold (95 \% CI 1.74-8.28, $P=0.001$ ) among individuals carrying two of the three homozygous risk genotypes (SNP1/GG*SNP2/CC, SNP2/CC*V115F/TT, SNP1/ $\mathrm{GG}^{*} \mathrm{~V} 115 \mathrm{~F} / \mathrm{TT}$ ) (Table 2). Furthermore, we found that among the participants with two homozygous risk genotypes, $91.43 \%$ of them were carrying both genotypes of SNP1/GG and V115F/TT. The other $8.57 \%$ were carrying both genotypes of SNP2/CC and V115F/TT.

In logistic regression models (adjusted by age and gender), the interaction between SNP1 and V115F was significantly associated with the susceptibility of obesity $(P=0.012)$. The interaction showed that individuals with both genotypes of SNP1/GG and V115F/TT were associated with 2.66-fold (95 \% CI 1.22-5.80, $P=0.012$ ) risk of obesity, compared with the others. The risk was increased to 3.21-fold when compared to participants with both genotypes of SNP1/TT and V115F/GG (95\% CI 1.337.73, $P=0.009$ ).

MDR analysis was also used to detect the interaction between the four tag-SNPs (V115F, SNP1, SNP2 and SNP4). Table 4 summarizes the best interaction models. In one-factor model, SNP2 was the best attribute for predicting obesity (testing accuracy $=54.58 \% ; \mathrm{CVC}=9$ / $10, P=0.377)$. SNP1 and SNP2 was the best two-factor model (testing accuracy $=53.56 \%, \quad \mathrm{CVC}=7 / 10$, $P=0.172$ ). However, by following the best model selected principle, the best model was determined to be a fourloci site model, which includes the polymorphisms of SNP1, SNP2, V115F and SNP4, with a maximum testing accuracy to $59.32 \%$ and a perfect CVC of $10 / 10$ $(P=0.011)$. Thus, the interaction dendrogram (Fig. 2) showed that these four SNPs linked by green lines were on the same branch, suggesting a synergistic interaction effect 1 on modulating the risk of obesity.

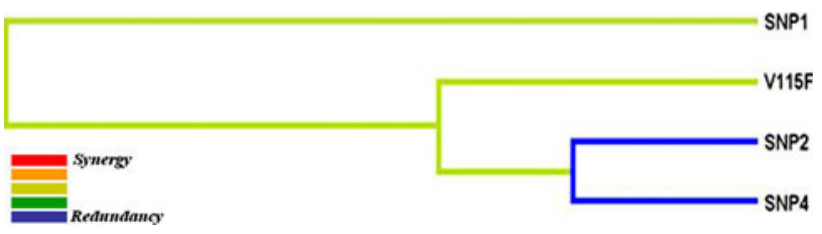

Fig. 2 Interaction dendrogram. The different color connections show the degree of interaction from synergy (red) to redundancy (blue)

\section{Discussion}

In this study, we genotyped five tag-SNPs in the CIDEA gene and investigated their associations with the risk of obesity in a Han Chinese population. We found that SNP1rs4796955/GG genotype, SNP2-rs8092502/CC genotype, V115F-rs11545881/TT genotype and haplotype GTTC were associated with an increased risk of obesity $(P<0.05)$. The MDR analysis identified a significant fourfactor interaction model including SNP1, SNP2, V115F and SNP4, suggesting that there was an interaction between the four SNPs. The logistic regression analysis (adjusted by age and gender) showed the interaction between SNP1 and V115F was significantly associated with the susceptibility of obesity.

Both human and mouse models show that CIDEA protein is emerging as an important regulator of the lipid metabolic pathway, and it plays important roles in lipid storage, lipid droplet format, lipolysis and the development of metabolic disorders such as obesity, diabetes mellitus, hepatic steatosis and cardiovascular diseases [7-9]. Mice with a deficiency in CIDEA were resistant to high-fat dietinduced obesity and diabetes mellitus with an increased metabolic rate, lipolysis in BAT and core body temperature when subjected to cold treatment, suggesting that CIDEA is important in energy expenditure in adipose tissues [7]. Their lean phenotype seems to be due to a loss of CIDEA protein direct suppression of uncoupling protein 1 (UCP1) activity in BAT [20]. However, there are some striking discrepancies between human and rodent CIDEA protein expression patterns. CIDEA protein is highly expression in BAT of rodent but in WAT of humans [8]. In contrast with the mouse model, CIDEA protein expression in humans is inversely associated with BMI, WC, WHR and basal metabolic rate. Some studies have reported that CIDEA protein
406 407 408 409 410 411 412 413 414 415 416 417 418 419 420 421 422 423 424 425 426 427 428 429 430 431 432 433 434 435 436 437 438
Table 4 Summary of the MDR interaction models

* $P<0.05$

\begin{tabular}{lllll}
\hline Model & $\begin{array}{l}\text { Training bal. } \\
\text { acc. }(\%)\end{array}$ & $\begin{array}{l}\text { Testing bal. } \\
\text { acc. }(\%)\end{array}$ & Sign test $(P)$ & CV consistency \\
\hline SNP2 & 57.49 & 54.58 & $6(0.377)$ & $9 / 10$ \\
SNP1SNP2 & 60.23 & 53.56 & $7(0.172)$ & $7 / 10$ \\
SNP1SNP2V115 & 63.23 & 54.75 & $9\left(0.011^{*}\right)$ & $7 / 10$ \\
SNP1SNP2V115SNP4 & 65.91 & 59.32 & $9\left(0.011^{*}\right)$ & $10 / 10$ \\
\hline
\end{tabular}

\begin{tabular}{lll} 
Journal : Large 11033 & Dispatch : 18-9-2013 & Pages : 9 \\
Article No. : $\mathbf{2 6 7 1}$ & $\square$ LE & $\square$ TYPESET \\
MS Code : MOLE-6442 & $\boldsymbol{\sim}_{\text {CP }}$ & $\checkmark$ DISK \\
\hline
\end{tabular}


expression was decreased two-fold in obese humans and normalized after weight reduction [9]. A study in 40 obese women showed that CIDEA gene expression is significantly up-regulated as a result of the energy-restricted diets intervention [21]. In contrast to the mechanism in mice, a study found that there is a cross-talk between CIDEA and TNF- $\alpha$ in human adipose tissue [9], and this has consequences for lipolysis. CIDEA decreases the availability of TNF- $\alpha$ by inhibiting cytokine secretion predominately through posttranscriptional mechanisms, which in turn counteracts the ability of TNF- $\alpha$ to stimulate lipolysis. TNF- $\alpha$ down-regulates the expression of CIDEA through signaling via c-Jun $\mathrm{NH}_{2}$-terminal kinase ( $\mathrm{JNK}$ ), which in turn increases the availability of TNF- $\alpha$ and thereby lipolytic stimulation [9]. In a recent energy restriction intervention study [8], a significant inverse correlation has been found between UCP1 and CIDEA expression levels, indicating a possible interaction between CIDEA and UCP1 in humans. CIDEA is also associated with insulin sensitivity in humans [22]. Recently, a study found that starvation-induced apoptosis in adipocytes is significantly inhibited when insulin decreased CIDEA mRNA expression levels, suggesting that CIDEA is a novel gene regulated by insulin in human adipocytes and that it may play a key role in obesity [23].

CIDEA polymorphisms have been reported to be associated with human obesity in Swedish, Japanese and Chinese populations. In this study, the $\mathrm{G}$ allele frequency of $\mathrm{V} 115 \mathrm{~F}$ was $49.39 \%$, which was lower than that previously reported in the Chinese $(55.25 \%)$ population and higher than reported in the Japanese $(48.90 \%)$ population [11, 12]. Multiple logistical regression results showed that participants with the TT genotype had a 2.84-fold (95\% CI 1.73-4.66, $P<0.001$ ) risk for obesity compared to those with the GG genotype. There was a trend that all the index levels of obesity related phenotypes in the participants were higher in the TT genotype group compared to the GG genotype groups (TT $>$ GT $>$ GG). Both genetic and continuous variable analyses indicated that the $\mathrm{T}$ allele of $\mathrm{V} 115 \mathrm{~F}$ SNP was a risk factor for obesity in Chinese. This result is consistent with our previous studies in both Japanese [11] and Chinese studies [12], but conflicts with the Swedish study [10]. This result could be due to the so-called "flip-flop" phenomenon, where, within differing ethnic groups, disease marker associations with reversed risk alleles are found [24, 25].

The possible impact of amino acid substitution of $\mathrm{V} 115 \mathrm{~F}$ on the structure and function of CIDEA protein would be benign based on the POLYPHEN analysis [12]. We considered that there might be some other causal variants at this locus, whose polymorphism, interaction or linkage disequilibrium could contribute to obesity; therefore, we further genotyped another four tag-SNPs of the CIDEA gene to test our hypotheses.
In single locus analysis, we found that two other new SNPs (SNP1 and SNP2) were associated with obesity. Subjects with SNP1/GG and SNP2/CC genotypes had higher levels of WC, and were associated with 2.19-fold and 4.37-fold increased susceptibility to obesity when compared with other genotype groups. Both SNP1 and SNP2 were intronic polymorphisms whose functions were not known. However, there have been reports about the association between intronic polymorphisms and different diseases [26-28]. For example, it was reported that up to $40 \%$ of transcription factor binding sites are located within introns. The exact molecular mechanisms of how the SNP1 and SNP2 variants affect obesity are unknown and require further investigation.

In haplotype analysis, we found that haplotype GTTC had 1.41-fold risk, while haplotype TTGC was a protective factor for obesity. Not surprisingly, the differences between haplotype GTTC and TTGC were associated with SNP1 G/T and V115F G/T alleles. Both of these risk alleles (SNP1/G and $\mathrm{V} 115 \mathrm{~F} / \mathrm{T}$ ) contributed to the risk haplotype of GTTC, while the protective alleles (SNP1/T and V115F/G) contributed to the haplotype TTGC. Logistic regression analysis found that there was a statistically significant interaction between these two SNPs, and participants with both SNP1/GG and V115F/ TT genotypes had 2.66-fold risk of developing obesity.

There is significant evidence showing that complex diseases are induced by gene-gene, gene-environmental and gene-environmental-behavior interactions. It is conceivable that obesity is the result of interactions between multiple genetic variations. In this study, the combined results of the nonparametric MDR approach and the parametric logistic analysis (adjusted by age and gender) indicated that the interaction between SNP1/GG and V115F/TT could increase the susceptibility of obesity occurring. Although our data cannot explain the biological mechanism, the result suggests that an interaction model could provide guidance to experimental studies on the metabolic pathway of obesity.

For this population screening study, 903 specimen collection paper was used to collect finger blood, which causes less discomfort to the subjects. The dried blood spots needed minimal storage space, caused little biohazard risk and were convenient for transportation [14]. The method also had the disadvantage of not having fresh blood samples for blood biochemical analyses such as triglyceride, total cholesterol, high density lipoprotein, which are associated with lipolysis. There were other limitations in our study. Firstly, the confounding factors such as diet, physical activity and environment were not considered. Secondly, all the associations offered in this study were a population-genetics based approach supported by statistical analyses, and therefore the explanation of the biological mechanism of obesity needs further investigation. Furthermore, recent interesting findings collectively highlight the complicated metabolite profiles in

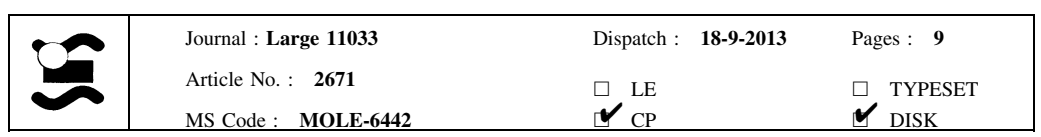


obesity at omics level, inspiring that post-genomics complementary approaches in obesity research are needed [29].

In conclusion, this is the first attempt to haplotype four SNPs in the CIDEA gene in a Han Chinese population, and we found that SNP1-rs4796955, SNP2-rs8092502, V115Frs11545881, haplotype GTTC and haplotype TTGC were associated with the susceptibility of obesity. The strong interaction between SNP1 and V115F could play a joint role in the development of obesity. Further studies with ethnically diverse populations and functional evaluation are warranted to confirm our findings.

Acknowledgments All participants that enrolled in this study were gratefully acknowledged. This work was financially supported by the Grants from Natural Science Foundation of China (30800949, 81273170), the China National "12th Five-Year" Plan for Science and Technology Support (2012BAI37B03), the China National High Technology Research and Development Program-863 (2006AA02Z434), Beijing Municipal Commission of Education (SQKM201210025010), Novel Star of Science Program, Beijing, China (2009A47), China Scholarship Council (2012-6021), Beijing Municipal Commission of Education for Overseas Students (2011-No165), Academic Human Resources Development in Institutions of Higher Learning Under the Jurisdiction of Beijing Municipality, PHR (IHLB) (PXM2011_014226_ 07_000028) the Australia-China Sciences Research Foundation (ACSRF06444), and the Importation and Development of High-Caliber Talents Project of Beijing Municipal Institutions.

\section{References}

1. Stunkard AJ, Sørensen TIA, Hanis C et al (1986) An adoption study of human obesity. N Engl J Med 314:193-198

2. Bouchard C, Tremblay A, Després JP et al (1990) The response to long-term overfeeding in identical twins. $\mathrm{N}$ Engl $\mathrm{J}$ Med 322:1477-1482

3. Chagnon YC, Rice T, Pérusse L et al (2001) Genomic scan for genes affecting body composition before and after training in Caucasians from HERITAGE. J Appl Physiol 90:1777-1787

4. Chen W, Li S, Cook NR et al (2004) An autosomal genome scan for loci influencing longitudinal burden of body mass index from childhood to young adulthood in white sibships: the Bogalusa heart study. Int J Obes Relat Metab Disord 28:462-469

5. Parker A, Meyer J, Lewitzky S et al (2001) A gene conferring susceptibility to type 2 diabetes in conjunction with obesity is located on chromosome 18p11. Diabetes 50:675-680

6. Inohara N, Koseki T, Chen S et al (1998) CIDE, a novel family of cell death activators with homology to the $45 \mathrm{kDa}$ subunit of the DNA fragmentation factor. EMBO J 17:2526-2533

7. Zhou Z, Yon Toh S, Chen Z et al (2003) Cidea-deficient mice have lean phenotype and are resistant to obesity. Nat Genet 35:49-56

8. Gummesson A, Jernås M, Svensson PA et al (2007) Relations of adipose tissue CIDEA gene expression to basal metabolic rate, energy restriction, and obesity: population-based and dietary intervention studies. J Clin Endocrinol Metab 92:4759-4765

9. Nordström EA, Rydén M, Backlund EC et al (2005) A humanspecific role of cell death-inducing DFFA (DNA fragmentation factor- $\alpha$ )-like effector A (CIDEA) in adipocyte lipolysis and obesity. Diabetes 54:1726-1734

10. Dahlman I, Kaaman M, Jiao H et al (2005) The CIDEA gene $\mathrm{V} 115 \mathrm{~F}$ polymorphism is associated with obesity in Swedish subjects. Diabetes 54:3032-3034
11. Zhang L, Miyaki K, Nakayama T et al (2008) Cell deathinducing DNA fragmentation factor [alpha]-like effector A (CI$D E A)$ gene $\mathrm{V} 115 \mathrm{~F}(\mathrm{G}->\mathrm{T})$ polymorphism is associated with phenotypes of metabolic syndrome in Japanese men. Metabolism 57:502-505

12. Zhang L, Dai Y, Bian L et al (2011) Association of the cell deathinducing DNA fragmentation factor alpha-like effector A (CI$D E A)$ gene $\mathrm{V} 115 \mathrm{~F}(\mathrm{G} / \mathrm{T})$ polymorphism with phenotypes of metabolic syndrome in a Chinese population. Diabetes Res Clin Pract 91:233-238

13. Zhopu BF, Cooperative Meta-Analysis Group of Working Group on Obesity in China (2002) Predictive values of body mass index and waist circumference for risk factors of certain related diseases in Chinese adults: study on optimal cut-off points of body mass index and waist circumference in Chinese adults. Biomed Environ Sci 15:83-96

14. Zhang J, Zhang L, Song MS et al (2010) Detection of HBV-DNA in dried bloodstains on filter paper by nested polymerase chain reaction. Lab Med 41:535-539

15. Jurinke C, van den Boom D, Cantor CR et al (2001) Automated genotyping using the DNA MassArray ${ }^{\mathrm{TM}}$ technology. Methods Mol Biol 170:103-116

16. Söderlund-Strand A, Dillner J, Carlson J (2008) High-throughput genotyping of oncogenic human papilloma viruses with MALDITOF mass spectrometry. Clin Chem 54:86-92

17. Schaeffeler E, Zanger UM, Eichelbaum M et al (2008) Highly multiplexed genotyping of thiopurine $S$-methyltransferase variants using MALDI-TOF mass spectrometry: reliable genotyping in different ethnic groups. Clin Chem 54:1637-1647

18. Barrett JC, Fry B, Maller J et al (2005) Haploview: analysis and visualization of LD and haplotype maps. Bioinformatics 21:263-265

19. Ritchie MD, Hahn LW, Roodi N et al (2001) Multifactordimensionality reduction reveals high-order interactions among estrogen-metabolism genes in sporadic breast cancer. Am J Hum Genet 69:138-1347

20. Lin SC, Li P (2004) CIDE-A, a novel link between brown adipose tissue and obesity. Trends Mol Med 10:434-439

21. Dahlman I, Linder K, Nordström EA et al (2005) Changes in adipose tissue gene expression with energy-restricted diets in obese women. Am J Clin Nutr 81:1275-1285

22. Puri V, Ranjit S, Konda S et al (2008) Cidea is associated with lipid droplets and insulin sensitivity in humans. Proc Natl Acad Sci USA 105:7833-7888

23. Ito M, Nagasawa M, Hara T et al (2010) Differential roles of CIDEA and CIDEC in insulin-induced anti-apoptosis and lipid droplet formation in human adipocytes. J Lipid Res 51:1676-1684

24. Tan EK, Tan C, Shen H et al (2003) Alpha synuclein promoter and risk of Parkinson's disease: microsatellite and allelic size variability. Neurosci Lett 336:70-72

25. Chartier-Harlin MC, Kachergus J, Roumier C et al (2004) Alphasynuclein locus duplication as a cause of familial Parkinson's disease. Lancet 364:1167-1169

26. Zhang Z, Wang S, Wang $M$ et al (2008) Genetic variants in RUNX3 and risk of bladder cancer: a haplotype-based analysis. Carcinogenesis 29:1973-1978

27. Sano M, Kuroi N, Nakayama T et al (2005) Association study of calcitonin-receptor-like receptor gene in essential hypertension. Am J Hypertens 18:403-408

28. Lehman DM, Fu DJ, Freeman AB et al (2005) A single nucleotide polymorphism in MGEA5 encoding $O$-GlcNAc-selective $N$ acetyl- $\beta-d$ glucosaminidase is associated with type 2 diabetes in Mexican Americans. Diabetes 54:1214-1221

29. Szymańska E, Bouwman J, Strassburg K et al (2012) Genderdependent associations of metabolite profiles and body fat distribution in a healthy population with central obesity: towards metabolomics diagnostics. OMICS 16:652-667

$\begin{array}{lll}\text { Journal : Large 11033 } & \text { Dispatch : 18-9-2013 } & \text { Pages : 9 } \\ \text { Article No. : } \mathbf{2 6 7 1} & \square \text { LE } & \square \text { TYPESET } \\ \text { MS Code : MOLE-6442 } & \sim_{\text {CP }} & \checkmark \text { DISK }\end{array}$


Journal : 11033

Article : 2671

\section{Author Query Form}

\section{黛 Springer}

the language of science

\section{Please ensure you fill out your response to the queries raised below and return this form along with your corrections}

\section{Dear Author}

During the process of typesetting your article, the following queries have arisen. Please check your typeset proof carefully against the queries listed below and mark the necessary changes either directly on the proof/online grid or in the 'Author's response' area provided below

\begin{tabular}{|l|l|l|}
\hline Query & Details Required & Author's Response \\
\hline AQ1 & $\begin{array}{l}\text { As per the information provided by the publisher, Fig. [2] will be black and white in print; hence, please } \\
\text { confirm whether we can add “colour figure online” to the caption. }\end{array}$ & Yes \\
\hline
\end{tabular}

